\title{
Reseña
}

\section{Parenti, L. R. y M. C. Ebach. 2009. Comparative biogeography: discovering and classifying biogeographical patterns of a dynamic Earth} University of California Press, Berkeley y Los Angeles. 291 p.

\author{
Tania Escalante* y Juan J. Morrone
}

Museo de Zoología "Alfonso L. Herrera", Departamento de Biología Evolutiva, Facultad de Ciencias, Universidad Nacional Autónoma de México, Apartado Postal 70-399, 04510 México, D.F., México.

*Correspondencia: tee@ibiologia.unam.mx

En las décadas pasadas se publicaron numerosos debates acerca de la existencia de la biogeografía como una ciencia independiente, así como de las diversas disciplinas que involucra y su interrelación con otras ciencias (Morrone, 2009). Aunque en esta discusión aún no existen consensos, muchos autores aceptan que la biogeografía pertenece a la biología comparada. Ésta última, estudia la biodiversidad y la explica a través de la teoría de la evolución en 2 dimensiones: tiempo y espacio, incluyendo desde la compilación y ordenamiento de datos acerca del mundo viviente, hasta su interpretación (Nelson y Platnick, 1981; Wiley, 1981). Sin embargo, para los autores del presente libro, la biogeografía, en sí misma, es comparada. Esto representa una visión novedosa que no existe en los textos actuales de biogeografía. Siguiendo su enfoque, uno de los objetivos fundamentales de la biogeografía comparada es diagnosticar y clasificar las áreas biogeográficas, examinando empíricamente los procesos históricos que explican los patrones de distribución. Así, la biogeografía comparada incorpora a la biogeografía sistemática y a la evolutiva (systematic biogeography y evolutionary biogeography).

El libro está conformado por una introducción y tres partes: (1) historia y homología, (2) métodos, e (3) implementación. Además, incluye un glosario. Se estructura de tal forma, que ofrece al lector una guía que incluye fundamentos teóricos, metodológicos y prácticos, en ese orden.

En la primera parte (capítulos 2, 3 y 4) se presentan conceptos biogeográficos básicos, como mapa biogeográfico, homología de áreas, clasificación natural, endemismo, areagrama y paralogía geográfica, entre otros. Los conceptos presentados incluyen novedades en

Recibido: 25 enero 2010; aceptado: 08 febrero 2010 esta materia, así, los autores hacen algunas distinciones interesantes, por ejemplo entre mapa biogeográfico y mapa de distribución geográfica, aunque otras, como la distinción entre área endémica y área de endemismo, seguramente generarán controversia. En general, creemos que serán importantes para contribuir a una futura clarificación de algunas ambigüedades que aún perduran en la biogeografía.

En la segunda parte (capítulos 5, 6 y 7) se presentan los métodos actuales en biogeografía, con énfasis en lo que los autores denominan el "método biogeográfico sistemático". El capítulo 5 bien podría haberse ubicado en la primera parte del libro, ya que también incluye discusiones teóricas, como la diferencia entre conceptos como patrón, proceso y mecanismo, límite y barrera, vicarianza y dispersión, e incluso entre vicarianza descriptiva y explicativa. Resultan interesantes otras distinciones conceptuales, como entre areagrama y cladograma taxonómico de áreas, aunque la mayoría de los biogeógrafos cladistas habrán de disentir. Los capítulos 6 y 7 son estrictamente metodológicos. Un cuadro que resume su contenido se muestra en la página 120 , donde los autores presentan su visión de la clasificación de los métodos de la biogeografía sistemática y evolutiva. En este cuadro los autores clasifican desde los mapas de distribución, pasando por el modelado de nichos ecológicos, hasta la filogeografía comparada (el primero y el último en los extremos "históricos", siendo el primero del año 1777 y el último del 2005). Si bien existen otras clasificaciones en la literatura, ésta resulta novedosa porque sólo asigna a la biogeografía cladística al análisis de componentes, los supuestos 1 y 2 , y el análisis de subárboles libres de paralogía. Por otro lado, también presentan una clasificación de las "aplicaciones biogeográficas" pertenecientes a los enfoques sistemático y evolutivo. El capítulo 7 se refiere exclusivamente al método 
de la biogeografía sistemática, cuyo objetivo es encontrar la monofilia de las áreas analizadas. Así, los conceptos presentados en los capítulos anteriores se materializan a través de las técnicas adecuadas para su descubrimiento. En este sentido, la integración de información de otras disciplinas, como la geología, permitirá iluminar los datos biogeográficos y sistemáticos.

La tercera y última parte (capítulos 8, 9 y 10), está dedicada a poner en contexto (el "mundo real", por así decirlo) los resultados de un análisis biogeográfico. Los autores incorporan conceptos geológicos y discuten la iluminación recíproca entre biogeografía (sistemática) y geología, además, se presenta el caso de estudio de la biota del Pacífico. El último capítulo llamado "El futuro de la biogeografía", se presenta como un corolario de la idea de la biogeografía comparada como una ciencia independiente, integral y con un lenguaje común.

Definitivamente es un libro que requiere una lectura cuidadosa, ya que puede representar un cambio en la forma de percibir algunos fenómenos biogeográficos. Desde nuestro punto de vista, el libro refleja una visión biogeográfica moderna y no exenta de polémicas, que seguramente habrá de interesar a biogeógrafos y otros profesionales que analizan la biodiversidad.

\section{Literatura citada}

Morrone, J. J. 2009. Evolutionary biogeography: An integrative approach with case studies. Columbia University Press, Nueva York. 301 p.

Nelson, G. y N. Platnick. 1981. Systematics and biogeography: Cladistics and vicariance. Columbia University Press, Nueva York. 567 p.

Wiley, E. O. 1981. Phylogenetics: The theory and practice of phylogenetic systematics. John Wiley and Sons, Nueva York. 439 p. 